\title{
Is botulinum toxin injection of the pylorus during Ivor-Lewis esophagogastrectomy the optimal drainage strategy?
}

\author{
Robert James Cerfolio, MD, FACS, FCCP, ${ }^{a}$ Ayesha S. Bryant, MSPH, MD, ${ }^{\mathrm{b}}$ Cheri L. Canon, MD, ${ }^{\mathrm{c}}$ Roopa Dhawan, BS, ${ }^{\mathrm{d}}$ \\ and Mohamad A. Eloubeidi, MD ${ }^{\mathrm{e}}$
}

Background: The optimal management of the pylorus during esophagogastrectomy is unknown. Pyloromyotomy and pyloroplasty cause early edema and risk long-term bile reflux; however, the lack of pyloric drainage might risk early aspiration.

\begin{abstract}
Methods: We performed a retrospective study with a prospective database on patients with esophageal cancer or high-grade dysplasia who underwent Ivor-Lewis esophagogastrectomy. All had one surgeon and similar stomach tubularization, hand-sewn anastomoses, nasogastric tube duration, and postoperative prokinetic agents. Outcomes of postoperative gastric emptying, aspiration, and swallowing symptoms were compared.
\end{abstract}

Results: Between January 1997 and June 2008, there were 221 patients. Seventy-one patients had a pyloromyotomy, and gastric emptying judged on postoperative day 4 was delayed in $93 \%$ (52\% had any morbidity and $14 \%$ had respiratory morbidity). Fifty-four patients had no drainage procedure, and gastric emptying was delayed in $96 \%$ (59\% had any morbidity and 22\% had respiratory morbidity). Twenty-eight patients underwent pyloroplasty, and 96\% had delayed gastric emptying (50\% had any morbidity and 32\% had respiratory morbidity). Sixty-eight patients had botulinum toxin injection into the pylorus. Gastric emptying was delayed in only $59 \%(P=.002,44 \%$ had any morbidity and 13\% had respiratory morbidity). Hospital length of stay $(P=$ $.015)$ and operative times $(P=.037)$ were shorter in the botulinum toxin group. Follow-up (mean, 40 months) showed symptoms of biliary reflux to be lowest in the botulinum toxin group $(P=.024)$.

Conclusion: Injection of the pylorus with botulinum toxin at the time of esophagogastrectomy is safe and decreases operative time when compared with pyloroplasty or pyloromyotomy. In addition, it can improve early gastric emptying, decrease respiratory complications, shorten hospital stay, and reduce late bile reflux. A prospective multi-institutional randomized trial is needed.

\begin{abstract}
Although esophagectomy for cancer is a well-established operation, there exists much controversy as to the optimal surgical approach and management of the pylorus. Many who prefer pyloroplasty argue that it helps gastric emptying associated with pyloric denervated and hence reduces the risk of pulmonary aspiration. ${ }^{1,2}$ However, it renders the pylorus incompetent and risks life-long bile reflux after esophagogastrectomy. In contrast, it has been argued that other techniques, such as pyloromyotomy or even no-pyloric-drainage procedures, are preferred. We have practiced all 3 techniques and have found that none are ideal. Although a pyloromyotomy and pyloroplasty help the vagectomized and denervated stomach empty, there is often edema after this procedure, and this
\end{abstract}

\footnotetext{
From the Section of Thoracic Surgery, Division of Cardio-Thoracic Surgery, Department of Surgery ${ }^{\mathrm{a}}$; the Division of Cardio-thoracic Surgery, Department of Surgery ${ }^{\mathrm{b}}$; the Department of Radiologyc; the University of Alabama School of Medicine ${ }^{\mathrm{d}}$; and the Division of Gastroenterology, Department of Medicine, ${ }^{\mathrm{e}}$ University of Alabama at Birmingham, Birmingham, Ala.

Read at the Thirty-fourth Annual Meeting of the Western Thoracic Surgical Association, Kona, Hawaii, June 25-28, 2008.

Received for publication June 23, 2008; revisions received Aug 7, 2008; accepted for publication Aug 30, 2008.

Address for reprints: Robert J. Cerfolio, MD, FACS, FCCP, Division of Cardiothoracic Surgery, University of Alabama at Birmingham, 703 19th St S, ZRB 739, Birmingham, AL 35294 (E-mail: Robert.cerfolio@ccc.uab.edu).

J Thorac Cardiovasc Surg 2009;137:565-72

$0022-5223 / \$ 36.00$

Copyright (c) 2009 by The American Association for Thoracic Surgery

doi:10.1016/j.jtcvs.2008.08.049
}

often prolongs gastric emptying in the early postoperative period when the patient is at the highest risk of aspiration. In addition, it can lead to long-term bile reflux, for which there is no satisfactory treatment. Conversely, if the pylorus is left alone so as to avoid long-term bile reflux, the stomach often does not empty well initially, and hence the risk of aspiration remains increased. Aspiration and aspiration pneumonia are the most common and devastating early postoperative complications after esophagogastrectomy ${ }^{3,4}$ and have remained a vexing problem in our practice. For these reasons, we postulated that the intraoperative injection of Botulinum A $100 \mathrm{U}$ toxin (Allergan Pharmaceuticals, Westport, Ireland), or what is more commonly called Botox, at the time of esophagogastrectomy might represent a promising solution to this controversial but clinically important dilemma. Botox can promote gastric empting for a few months after surgical intervention, thereby reducing the risk of aspiration when it is most likely and most lethal, but it should not cause long-term bile reflux because its effects dissipate within a few months. We evaluated our preliminary experience using Botox injection into the pylorus at the time of esophagogastrectomy.

\section{MATERIALS AND METHODS}

This is a retrospective cohort study of a prospective database of a consecutive series of patients with distal or midesophageal cancer or those with high-grade dysplasia who underwent Ivor-Lewis esophagogastrectomy performed by one surgeon in an academic setting (the University 
of Alabama at Birmingham, Birmingham, Ala). All patients had their stomachs tubularized in the same fashion. The fundus of the stomach, the gastroesophageal junction, and the proximal portion of the lesser curve were all removed with a stapling device. This staple line was then oversewn. The conduit's width was approximately $6 \mathrm{~cm}$ in all patients, and the anastomosis was constructed through an end of the esophagus to the side of the stomach. The conduit was constructed so as not to be redundant, to sit straight in the posterior mediastinal bed, and to have approximately 3 $\mathrm{cm}$ of stomach above the anastomosis. A standard Ivor-Lewis esophagogastrectomy was performed, ${ }^{5}$ and a hand-sewn anastomosis of the end of the esophagus to the side of the stomach above the azygous vein was constructed in all patients. Patients younger than 19 years of age or those who underwent esophagogastrectomy for reasons other than dysplasia or malignancy were excluded. In addition, patients who underwent a transhiatal or 3-hole ${ }^{6}$ esophagogastrectomy or a total esophagectomy with gastric pull-up with a gastric-pharyngeal anastomosis were also excluded from this study to decrease the effect that the location of the anastomosis or remaining amount of native esophagus might have on emptying. Early outcomes assessed and compared were operative times, morbidity rates, operative mortality, gastric emptying, incidence of anastomotic leak, and hospital length of stay. Late outcomes included the incidence of bile reflux symptoms, as assessed by survey, and stricture rates, as assessed based on the need for anastomotic dilation. Clinically significant bile reflux was assessed at the time of the 3-week postoperative clinic visit; at 3,6, and 9 months; and yearly thereafter by telephone. The specific questions used to identify bile reflux were the patient's reporting of nausea, vomiting after or while eating, and/or the sensation of bland liquid regurgitating cranially, pillow staining of dark material during sleep, or both.

For the purposes of this study, aspiration was defined as a patient with altered eating habits or choking and/or coughing symptoms while swallowing, clinical assessment consistent with aspiration in which medical intervention was indicated (eg, urgent intubation, followed by bronchoscopy, antibiotics, oxygen, and suction), or both. Pneumonia was defined as radiographic findings of an infiltrate with an increased white blood cell count and a fever along with clinical manifestation of respiratory distress (dyspnea, hypoxia, and infection documented clinically or microbiologically) with no evidence of an aspiratory event. ${ }^{7}$ Operative mortality includes any patient who died during his or her hospital stay or for any reason 30 days after discharge. Weight change was defined as body weight at the time of the 3week postoperative follow-up visit subtracted from weight at the time of hospital discharge.

\section{Upper Gastrointestinal Swallow on Postoperative Day 4}

Gastric emptying was assessed by using an upper gastrointestinal swallow performed on postoperative day 4 . The study started with the patient drinking 50 to $75 \mathrm{~mL}$ of a water-soluble contrast agent. This was followed by the drinking of 30 to $60 \mathrm{~mL}$ of barium contrast agent. In addition to the use of fluoroscopy to assess swallowing, digital spot images were obtained in multiple obliquities in both the upright and supine positions. A single gastrointestinal radiologist who was blinded to the type of pyloric procedure performed retrospectively reviewed all of the studies and classified them in one of 5 categories. The first category was labeled as "no delay" and was defined as complete emptying of all contrast administered into the proximal duodenum within 2 minutes. The second category, labeled "slight delay," was defined as emptying of all contrast material within 5 minutes. The third category, labeled "mild delay," was defined by complete emptying of the oral contrast into the duodenum at 10 minutes. The fourth category, labeled "moderate delay," was defined as the emptying of $50 \%$ or more of the contrast at 10 minutes. The fifth and final category, labeled "significant delay," was defined as less than $50 \%$ emptying of the contrast after 10 minutes. These latter patients had a nasogastric tube temporarily reinserted, and the contrast agent was removed. For statistical purposes, we then grouped patients as having one of 3 levels of gastric emptying, as shown in
TABLE 1. Definitions of gastric emptying on postoperative day 4 swallow study

\begin{tabular}{lllc}
\hline Category & Descriptor & \multicolumn{1}{c}{ Definition } & Level \\
\hline 1 & None & Prompt emptying, usually $<2$ min & 1 \\
2 & Slight & Majority of emptying $(>90 \%)$ in 2-5 min & 2 \\
3 & Mild & $\begin{array}{l}\text { Majority of emptying }(>90 \%) \text { in } \\
\text { 6-10 min }\end{array}$ \\
4 & Moderate & $\begin{array}{l}\text { Slow emptying over a period of 10 } \\
\text { minutes, usually 25\% to 90\% emptied }\end{array}$ & 3 \\
& & in 10 min \\
5 & Significant & $\begin{array}{l}\text { Little to no emptying, almost all contrast } \\
\text { remaining at 10 min }\end{array}$ \\
\hline
\end{tabular}

Table 1. Level 1 indicated no delay and included only patients with category 1 emptying. Level 2 included patients with category 2 or 3 emptying, and level 3 included patients with category 4 or 5 emptying. This study and the prospective database were both approved by the University of Alabama at Birmingham's Institutional Review Board. Patient contest was obtained for entry into the prospective database but was waived for this study.

\section{Statistical Analysis}

Data were analyzed by using the Student $t$ test and Wilcoxon and $\chi^{2}$ tests, as appropriate. A stepwise multivariate logistic regression model was used to correct for the effect of multiple variables and their interactions for delay of gastric emptying. Variables that were associated with gastric emptying delay with a $P$ value of less than .1 in the univariate analysis were entered into the multivariate model. Software used was SAS version 9.1 (SAS Institute, Inc, Cary, NC).

\section{Operative Technique}

Ivor-Lewis esophagogastrectomy was accomplished through a 2-stage operation, starting with a midline exploratory laparotomy incision with mobilization of the stomach based on the right gastroepiploic artery. The second phase consisted of a right posterior lateral thoracotomy, as previously described. $^{4,5}$ The pylorus was treated in 4 different ways during the abdominal portion of the operation in this study. Each patient received only 1 therapy. Patients either had their pylorus left alone (also referred to as undergoing no drainage procedure); underwent a pyloromyotomy or pyloroplasty, as previously described ${ }^{8}$; or had botulinum toxin (Botox) injection of the pylorus. The latter procedure, not previously described intraoperatively, was accomplished by diluting $0.4 \mathrm{~mL}$ of Botulinum A $100 \mathrm{U}$ toxin (Allergan Pharmaceuticals) with $4 \mathrm{~mL}$ of normal saline. One milliliter of the mixture was then injected into the muscle of all 4 quadrants of the pylorus during the operation by using a 22 -gauge needle. This was done by the operating surgeon and was not performed endoscopically.

\section{Botulinum Toxin}

In striated muscle botulinum toxin inhibits acetylcholine from cholinergic nerves. Botulinum toxin A selectively cleaves the synaptosomal-associated protein 25 , leading to the inability of synaptic vesicles containing neurotransmitters to undergo exocytosis and release neurotransmitters. ${ }^{9}$ In gastrointestinal smooth muscle botulinum toxin appears to also reduce cholinergic transmission by inhibiting acetylcholine release, as shown in in vitro ${ }^{10}$ and in vivo ${ }^{11}$ studies. Synaptosomal-associated protein 25 is also present in gastrointestinal smooth muscle, suggesting an additional site for botulinum toxin. Although the exact mechanism of botulinum toxin in the smooth muscles is currently unknown, we do know that botulinum toxin injection into the lower esophageal sphincter decreases lower esophageal sphincter tone and improves symptoms in achalasia. ${ }^{11}$ Botulinum 
TABLE 2. Patient characteristics by pylorus treatment type

\begin{tabular}{|c|c|c|c|c|c|c|}
\hline & \multicolumn{3}{|c|}{ Pre-Botox group } & \multirow{2}{*}{$\begin{array}{c}\text { Botox group } \\
\text { Botulinum toxin injection }\end{array}$} & \multirow[b]{2}{*}{$P$ value* } & \multirow[b]{2}{*}{ Totals } \\
\hline & Pyloroplasty & Pyloromyotomy & No drainage & & & \\
\hline No. of patients & 28 & 71 & 54 & 68 & NA & 221 \\
\hline Sex (male) & $20(71 \%)$ & $38(53 \%)$ & $37(69 \%)$ & $44(65 \%)$ & .823 & $139(63 \%)$ \\
\hline Dates performed & $\begin{array}{l}\text { January } 1997- \\
\text { December } 2000\end{array}$ & $\begin{array}{c}\text { January } 2001- \\
\text { June } 2005\end{array}$ & $\begin{array}{l}\text { July } 2005- \\
\text { October } 2006\end{array}$ & $\begin{array}{l}\text { November 2006- } \\
\text { June } 2008\end{array}$ & NA & $\begin{array}{c}\text { January } 1997- \\
\text { June } 2008\end{array}$ \\
\hline Median age (y [range]) & $64(23-74)$ & $56(43-76)$ & $58(25-88)$ & $64(41-74)$ & .46 & $61(23-88)$ \\
\hline Histology & & & & & NA & \\
\hline HGD & $1(4 \%)$ & $5(7 \%)$ & $6(11 \%)$ & $5(17 \%)$ & & $17(8 \%)$ \\
\hline Adenocarcinoma & $14(50 \%)$ & $36(51 \%)$ & $29(54 \%)$ & $39(59 \%)$ & & $118(53 \%)$ \\
\hline Squamous cell & $7(25 \%)$ & $16(23 \%)$ & $8(15 \%)$ & $11(16 \%)$ & & $42(19 \%)$ \\
\hline NOS & $6(21 \%)$ & $14(20 \%)$ & $11(20 \%)$ & $14(18 \%)$ & & $44(20 \%)$ \\
\hline $\begin{array}{l}\text { Neoadjuvant } \\
\text { chemoradiotherapy }\end{array}$ & $13(46 \%)$ & $40(56 \%)$ & $23(43 \%)$ & $39(57 \%)$ & .362 & $115(52 \%)$ \\
\hline Pathologic stage & & & & & .52 & \\
\hline HGD/CR & $8(29 \%)$ & $20(28 \%)$ & $18(33 \%)$ & $13(16 \%)$ & & $59(27 \%)$ \\
\hline I & $7(25 \%)$ & $26(37 \%)$ & $12(22 \%)$ & $28(44 \%)$ & & $73(33 \%)$ \\
\hline II & $6(21 \%)$ & $15(21 \%)$ & $20(37 \%)$ & $21(32 \%)$ & & $62(28 \%)$ \\
\hline III & $4(14 \%)$ & $7(10 \%)$ & $3(6 \%)$ & $6(12 \%)$ & & $20(9 \%)$ \\
\hline IV & $3(11 \%)$ & $3(4 \%)$ & $1(2 \%)$ & $0(0 \%)$ & & $7(3 \%)$ \\
\hline
\end{tabular}

$H G D$, High-grade dysplasia; $N O S$, not otherwise specified (usually in patients who were complete responders); $C R$, complete responder. ${ }^{*} P$ value compares all pre-Botox groups (pyloroplasty, pyloromyotomy, and no drainage) with the Botox group.

toxin injection into the pyloric sphincter is reported to improve gastric emptying and reduce dyspeptic symptoms in patients with gastroparesis. ${ }^{12,13}$ Its pharmacologic duration is described to be approximately 90 to 120 days.

\section{Postoperative Care}

Patient care was administered as previously described. ${ }^{4}$ In summary, patients went directly to the floor from the operating room, and the intensive care unit was not used as a routine. A nasogastric tube was placed at the time of the operation and was removed on the morning of postoperative day 3. Metoclopramide (Reglan, Baxter Pharmaceutical), erythromycin, and esomeprazol (Nexium, AstraZeneca Pharmaceuticals) were started on the day of the operation. Swallows were done on postoperative day 4. Patients were sent home on a 1-month course of erythromycin and a 3-month course of esomeprazol.

\section{RESULTS}

There were 221 patients with a median age of 64 years (range, 23-88 years) who underwent Ivor-Lewis esophagogastrectomy between January of 1997 and June of 2008 performed by one surgeon. Over this time period, there were 32 patients who underwent either transhiatal total esophagogastrectomy with gastric to pharyngeal anastomosis or thoracoabdominal or colonic interposition esophagogastrectomy who were not included in this study. Patient characteristics of the 221 patients are shown in Table 2 and stratified by the type of pyloric management. There were no significant differences in patient characteristics, comorbidities, and duration of nasogastric tube use between the pre-Botox (no pyloric manipulation, pyloroplasty, and pyloromyotomy) and Botox groups. On univariate analysis, age greater than 70 years $(P=.043)$, neoadjuvant chemoradiotherapy $(P=$ $.026)$, and the lack of Botox use $(P=.015)$ were predictors of level 3 gastric emptying. On multivariable analysis, neoadjuvant therapy $(P$ 0.031; odds ratio, $1.8 ; 95 \%$ confidence interval, 1.09-2.41) and the lack of Botox use $(P=.016$; odds ratio, 2.9; $95 \%$ confidence interval, 1.68-3.86) remained significant predictors of delayed gastric emptying. Table 3 shows the delay and postoperative morbidity experienced by patients in each group. It shows that only $59 \%$ of patients who received botulinum toxin experienced gastric delay on the postoperative day 4 swallow study. A significantly greater proportion of patients who underwent no drainage procedure, pyloromyotomy, or pyloroplasty had gastric delay compared with those who had Botox injected into their pylorus $(96 \%, 93 \%, 96 \%$, and $59 \%$, respectively; $P<.001)$. As shown in Table 3, hospital length of stay $(P=.015)$ and operative time $(P=.037)$ were shorter in the Botox group. Follow-up (mean, 40 months) showed symptoms of biliary reflux to be lowest in the Botox group $(P=.024)$. Patient weight decreased a median of $7.2 \mathrm{lbs}$ in the pre-Botox group and $4.9 \mathrm{lbs}$ in the Botox group $(P=.028)$. There was no relation between stricture rate and symptoms of biliary reflux or aspiration.

\section{DISCUSSION}

The ideal treatment of the pylorus during esophagogastrectomy is unknown. Determination of the optimal management is difficult because it is contingent on many protean factors. Some of these variables are the indication for esophagogastrectomy, the use of neoadjuvant chemoradiotherapy, the type of esophagogastrectomy performed, the manner in which the stomach is cut or stapled, the surgeon, the type 
TABLE 3. Early and late postoperative outcomes

\begin{tabular}{|c|c|c|c|c|}
\hline & Pyloroplasty & Pyloromyotomy & No drainage & Botulinum toxin \\
\hline No. of patients $(\%)$ & 28 & 71 & 54 & 68 \\
\hline Median duration of operation $(\mathrm{h})^{*}$ & 4.3 & 3.9 & 3.5 & 3.3 \\
\hline Gastric delay on postoperative day 4 swallow $\dagger$ & $96 \%$ & $93 \%$ & $96 \%$ & $59 \%$ \\
\hline Level 1 (no delay) $\dagger$ & $1(4 \%)$ & $5(7 \%)$ & $2(4 \%)$ & $27(41 \%)$ \\
\hline Level 2 delay ("slight", or "mild") $\dagger$ & $13(46 \%)$ & $22(32 \%)$ & $15(27 \%)$ & $19(28 \%)$ \\
\hline Level 3 delay ("moderate", or "severe") $\dagger$ & $14(50 \%)$ & $42(61 \%)$ & $37(69 \%)$ & $21(31 \%)$ \\
\hline Morbidity & $14(50 \%)$ & $32(52 \%)$ & $32(59 \%)$ & $30(44 \%)$ \\
\hline Pneumonia/aspiration & $9(32 \%)$ & $10(14 \%)$ & $12(22 \%)$ & $9(13 \%)$ \\
\hline Mortality & $1(4 \%)$ & $4(6 \%)$ & $2(4 \%)$ & $3(4.4 \%)$ \\
\hline Anastomotic leak & 0 & 0 & 1 & 0 \\
\hline Hospital length of stay, median (d) & 8.7 & 9.5 & 8.2 & 7.3 \\
\hline Symptoms of bile reflux & $10(38 \%)$ & $14(20 \%)$ & $5(9 \%)$ & $4(6 \%)$ \\
\hline Stricture (requiring dilation) & $4(14 \%)$ & $6(8.4 \%)$ & $4(7.4 \%)$ & $5(7.3 \%)$ \\
\hline
\end{tabular}

*Includes turning of patient for thoracotomy. $\dagger$ Does not total the number of patients in each group because of mortality before the postoperative day 4 swallow.

and location of the anastomosis, the location at which the conduit is positioned, the length of time the stomach is drained, the operative time, the point at which gastric emptying is studied, and the use of prokinetic agents. Although this series is unique in that all of these factors were essentially the same in each group over time, the study is nonrandomized, nuclear gastric emptying studies were not used, and swallowing was only radiologically assessed at one point in time. In addition, the patients who received botulinum toxin had all been operated on last when the surgeon and his team were the most experienced. However, the swallowing studies were done consistently in the same manner and at the same time (on postoperative day 4) and read by one radiologist who was blinded to the pyloric procedure. Despite these flaws, the results are provocative.

There have been several prospective studies that have attempted to answer the question of the ideal pyloric emptying procedure during esophagogastrectomy, but they too have all been either underpowered or flawed. In this study we have shown that intraoperative injection of Botox into the pylorus at the time of the resection shortens the operative time, is safe, and is easy to do. It might also help reduce gastric emptying delay and decrease bile reflux. A true multi-institutional study is needed to fully answer this important question, but its design must take into account some of the variables mentioned above, along with others. Once multiple surgeons are asked to participate in such a study, many other confounding variables are introduced. Despite the lack of perfect data to fully answer the controversial question of how to best handle the pylorus at the time of esophagogastrectomy, several important concepts are known.

Fok and colleagues, ${ }^{14}$ in 1991 , published the largest prospective randomized study on this issue. They randomized 200 patients: 100 received a pyloroplasty, and 100 received no drainage procedure. All patients had their whole stomachs used, and they all underwent a Lewis-
Tanner operation. ${ }^{15}$ Fok and colleagues ${ }^{14}$ reported that 13 patients who received no drainage procedure had gastric outlet obstruction, 1 required reoperation, and 4 experienced pulmonary complications, of which 2 died. This study would suggest that pyloric drainage, specifically pyloroplasty, is superior to no drainage for patients who undergo esophagogastrectomy when the entire stomach is the conduit selected. However, Mannell and associates, ${ }^{16}$ in 1990 , showed in a prospective randomized trial that pyloroplasty led to dumping syndrome and bile reflux. Although this report involved patients who had a gastric conduit placed retrosternally, the notion that a pyloroplasty might convert a unidirectional sphincter into a bidirectional nonvalved conduit is not new. Furthermore, leakage from a pyloromyotomy or pyloroplasty can occur, and this adds another possible complication. Because the pylorus often is located at the level of the diaphragm after esophagogastrectomy, a leak from a pyloromyotomy or pyloroplasty can be located in the chest, the abdomen, or both and can therefore be difficult to manage. In addition, Zieren et $\mathrm{al}^{17}$ in 1995 , showed that patients who undergo pyloroplasty can have a late pyloric stricture as well. Thus these procedures, although relatively safe, can lead to significant complications.

Given these reports and because pyloromyotomy has similar results (and sometimes a pyloromyotomy ends up turning into a pyloroplasty), we began omitting any type of pyloric drainage procedure during our Ivor-Lewis esophagogasrectomies. A recent study from Low ${ }^{18}$ reported a series of 301 patients who underwent esophagogastrectomy, of which 287 had no drainage procedure. The incidence of aspiration was exceedingly low in that study, and the operative mortality was only $0.3 \%$. These data and presentation led us to change our technique. Starting in July 2005, we began to eliminate the performance of any drainage procedure. This thinking was supported by others. Palmes and colleagues, ${ }^{19}$ in 2007, reported on 198 
patients and concluded that "pyloric drainage after esophagectomy with gastric conduit reconstruction should be omitted because it does not improve gastric emptying and may favor biliary reflux esophagitis." Similarly, Doning$\operatorname{ton}^{20}$ stated in 2006 that "the role of pyloric drainage and the control of reflux is a double edged sword. It seems to improve emptying but it also has the potential to increase reflux of bile from the duodenum." Thus we changed our technique and performed 54 consecutive Ivor-Lewis operations and omitted any type of pyloric drainage procedures. We left the pylorus alone. As shown in Table 2, we noted poor gastric emptying on our postoperative day 4 swallows, and $22 \%$ of patients had aspirations, pneumonias, or respiratory complications. We also had 2 mortalities, and both were due to aspiration. In our hands the technique of pylorus sparing was not successful. Because we had referred several of these patients who had poor gastric emptying for endoscopic Botox injection after surgical intervention, we then considered the idea of injecting Botox directly into the pylorus at the time of the operation ourselves while the abdomen was open. The concept was attractive to us because it theoretically might help promote gastric emptying during the time the patient was most at risk of aspiration (for a few months after the operation), and yet at the same time, it might avoid the long-term side effects of permanent pyloric drainage and subsequent bile reflux for which there is little effective therapy. Because we had no previous reference to go by, we used the dose of $0.4 \mathrm{~mL}$ of $100 \mathrm{U}$ of botulinum toxin diluted in $4 \mathrm{~mL}$ of normal saline with 4-quadrant injection because that was how our endoscopic colleagues delivered it from the stomachduodenal junction. We used the same dose and 4-quadrant injection, only we did it from the outside the pylorus into the muscle at the time of the laparotomy.

In the past 68 Ivor-Lewis esophagogastrectomies, we have performed intraoperative Botox injection, and the results have been good to excellent. Two of our gastrointestinal radiologists immediately noticed the difference in many (but not all) of our postoperative studies and inquired what we were doing differently to achieve such a dramatically different radiologic result. The edema from a pyloroplasty or pyloromyotomy was gone, and the poor gastric emptying we observed in patients who received no drainage procedure was also gone. Most importantly, the radiologic improvements translated into improved clinical outcomes. As seen in Table 2, the incidence of aspiration and pneumonias has been reduced, and patients have enjoyed improved functional swallowing results sooner and less bile reflux later. However, the results are not perfect.

The limitations of this study include the small sample size and lack of randomization. Moreover, the patients who received Botox also had the most experienced surgical team when compared with the other 3 groups of patients. The follow-up is not as long in the Botox group as it is in the other groups, and it is possible that some patients might not have yet had bile reflux. However, our follow-up seems long enough in a large number of patients based on the time it took the patients in the other groups to experience their bile reflux to show a significantly reduced rate.

Another potential limitation was that we used a questionnaire to assess bile reflux instead of radiologic studies. Although radiologic studies can be more sensitive, they are expensive and of little use if results are positive in a patient who is gaining weight and eating and swallowing well. The strengths of this study are the minimization of confounders, as described above, by using one surgeon and very similar intraoperative and postoperative techniques. Other strengths include the use of a prospective database, the construction of the conduit and anastomosis in the same manner and position, the same nasogastric tube duration, the same type and duration of prokinetic agents, the reading of all swallows by one radiologist who reviewed each patient's swallowing study, and performance of swallows on the same postoperative day in each patient. In addition, by eliminating other types of esophagogastrectomies in this study, we eliminated the possible effects that the location of the anastomosis or the amount of native esophagus left in place could have on our results.

In conclusion, in this preliminary nonrandomized retrospective study on 221 patients, we have shown that the intraoperative injection of botulinum toxin into the pylorus at the time of esophagogastrectomy is safe and effective and decreases the operative time of the Ivor-Lewis operation. In addition, we have provided provocative preliminary data that it might also improve the immediate emptying of the vagectomized stomach and decrease the operative morbidity by reducing the incidence of aspiration and pneumonia. This technique might also reduce length of stay as well. Further carefully designed prospective multi-intuitional studies are needed to answer this important clinical question, and this study might provide safety data for the framework for such a study.

\section{References}

1. Cheung HC, Siu KF, Wong J. Is pyloroplasty necessary in esophageal replacement by stomach? A prospective, randomized controlled trial. Surgery. 1987; 102:19-24.

2. Urschel JD, Blewett CJ, Young JE, Miller JD, Bennett WF. Pyloric drainage (pyloroplasty) or no drainage in gastric reconstruction after esophagectomy: a meta-analysis of randomized controlled trials. Digest Surg. 2002;19:160-4.

3. Atkins BZ, Shah AS, Hutcheson KA, et al. Reducing hospital morbidity and mortality following esophagectomy. Ann Thorac Surg. 2004;78:1170-6.

4. Cerfolio RJ, Bryant AS, Bass CS, Alexander JR, Bartolucci AA. Fast tracking after Ivor Lewis esophagogastrectomy. Chest. 2004;126:1187-94.

5. Patterson GA, Cooper JD, Deslauriers Lerat AE, Luketich JD, Rice TW. Esophagetomy via right thoracotomy. vol 2. 3rd ed. Philadelphia, PA: Churchill Living stone; 2008. p. 590-6.

6. McKeown KC. Total three-stage oesophagectomy for cancer of the oesophagus. Br J Surg. 1976;63:259-62.

7. National Institute of Health. Common terminology criteria for adverse events (CTCAE) v. 3.0; 2003:56-8.

8. Soreide JA, Soreide K. Heineke-Mikulicz, Finney. Pylorplasty. In: Operative techniques in general surgery. Vol. 5. p. 65-72. 
9. Blasi J, Chapman ER, Link E, et al. Botulinum toxin A selectively cleaves the synaptic protein SNAP-25. Nature. 1993;365:160-3.

10. MacKenzie I, Burnstock G, Dolly JO. The effects of purified botulinum neurotoxin type A on cholinergic, adrenergic and non-adrenergic, atropineresistant autonomic neuromuscular transmission. Neuroscience. 1982;7: 997-1006.

11. Pasricha PJ, Ravich WJ, Hendrix TR, Kaloo AV. Intrasphincteric botulinum toxin for the treatment of achalasia. N Engl J Med. 1995;332:774-8.

12. Ezzedine D, Jit R, Katz N, Gopalswamy N, Bhutani MS. Pyloric injection of botulinum toxin for treatment of diabetic gastroparesis. Gastrointest Endosc. 2002; 55:920-3.

13. Miller LS, Szych GA, Kantor SB, et al. Treatment of idiopathic gastroparesis with injection of botulinum toxin into the pyloric sphincter muscle. Am J Gastroenterol. 2002;97:1653-60.

14. Fok M, Cheng SW, Wong J. Pyloroplasty versus no drainage in gastric replacement of the esophagus. Am J Surg. 1991;162:447-52.

15. Ong GB, Kwong KH. The Lewis-Tanner operation for cancer of the oesophagus. J R Coll Surg Edinb. 1969;14:3-19.

16. Mannell A, McKnight A, Esser JD. Role of pyloroplasty in the retrosternal stomach: results of a prospective, randomized, controlled trial. Br J Surg. 1990;77: 57-9.

17. Zieren HU, Muller JM, Jacobi CA, Pichmaier L. Should a pyloroplasty be carried out in stomach transposition after subtotal esophagectomy with esophago-gastric anastomosis at the neck? A prospective randomized study. Chirurg. 1995;66: 319-32.

18. Low DE. Esophageal resection: improved outcomes associated with a diversified approach. Abstract read at: 31 st Annual Meeting of the Western Thoracic Surgical Association; June 22-25, 2008; Victoria, British Columbia, Canada.

19. Palmes D, Weilinghoff M, Colombo-Benkmann M, Senninger N, Bruewer M. Effect of pyloric drainage procedures on gastric passage and bile reflux after esophagectomy with gastric conduit reconstruction. Langenbecks Arch Surg. 2007;392: 135-41.

20. Donington JS. Functional conduit disorders after esophagectomy. Thorac Surg Clin. 2006;16:53-62.

\section{Discussion}

Dr Ross Bremner (Phoenix, Ariz). Thank you very much, and congratulations on yet another great presentation and certainly a very interesting and clearly written article.

The optimal drainage procedure for gastric interposition has been debated perhaps even longer than the optimal treatment for stage III lung cancer, but I will try to be brief. The idea of a quick Botox injection is indeed intriguing, and although you do not measure the time it takes to do the Botox procedure versus a formal pyloric procedure, I am sure your conclusion that it is quicker is probably correct. I do have a couple of questions.

How exactly do you do this? How expensive is the drug, and do you know intraoperatively that you have done it adequately? Can you feel that the muscle is now paralyzed?

Dr Cerfolio. Thank you, and those are good questions. We do not put a scope into the stomach and look endoscopically to ensure proper placement, if that is what you mean. We do it by touch. The pylorus is easily palpated. We inject Botox into it in all 4 quadrants, and we are very careful on the side next to the gastroepiploic artery. We inject the Botox in equal parts into all 4 quadrants. Because I had really no baseline to go on, no previous publications on this new idea to read, or anyone to ask, I just curb-sided my gastrointestinal guys and decided to copy what they were doing endoscopically and do it open at the time of laparotomy. You can see the Botox go into the pylorus; you get a little wheal when you are injecting it sort of in the submucosal area, and then I just sort of massage that in like a plastic surgeon does on the forehead. I have talked to a couple plastic surgeons, and I guess that is what they do when they do eyebrows and foreheads. Again, I just really made this up.

Dr Bremner. How expensive is it?

Dr Cerfolio. It is expensive. Actually, it is interesting that the billing office at the University of Alabama at Birmingham is very aggressive with our operative notes, and they actually bill for it. There is some code for chemodenervation of the muscle I see when I get these operative notes to sign, and therefore one can and should bill for it.

Dr Bremner. I am a little concerned about the temporary nature of Botox. From the experience of gastroparesis and endoscopic Botox, we know that it lasts just about 3 to 5 months. In our cases in which we have had to do a later operation to open up the pylorus for gastric emptying, it is usually done more than 6 months later. I wonder whether you have had any of your patients in whom you have had to do an endoscopic redo Botox procedure if they had gastric emptying problems?

Dr Cerfolio. We have not had to do that yet in the Botox group. Now we certainly have used Botox in the other patients who have very slow emptying, but I think that is much easier than a redo or first-time pyloromyotomy after esophagectomy when the pylorus is in no man's land at the level of the diaphragm. I have never gone back and had to reoperate on any of these patients for pyloric obstruction, but we have used Botox in the other group, especially in the group in which we did not do anything to the pylorus initially. I think it works. But in those in whom we have treated the pylorus initially with Botox, I have been thrilled with their emptying, even after 3 to 5 months.

Dr Bremner. Do you have a very narrow conduit?

Dr Cerfolio. We tubularize the conduit to about 5 or $6 \mathrm{~cm}$ in each patient. I think it is a real mistake to make the conduit too wide or too redundant. I keep the stomach straight and narrow and tall: a straight shot into the abdomen from the chest.

Dr Bremner. The study is unfortunately limited because you stated here and well in the article that the objective data on longterm emptying are not there, and I think it would be really nice if you could do a radiographic emptying study, even on a subsection of these patients. I mean, if you could just randomly select 20 patients from each of the groups and do an emptying study a year or 2 down the line, it would be really nice to see what that it looks like and perhaps even do a nuclear study to see whether there is any bile reflux. Do you plan on doing something like that?

Dr Cerfolio. You are right, and we have some data on some of the patients, but as I told Ayesha (and we all know Ayesha, she was supposed to present this), unless you have the data for all the patients, it does not make sense to show them for some patients. We really have data for only a few patients who were having problems. I would argue that I am in this to take care of the patient. If the patient is happy and swallowing well and maintaining his or her weight, I do not care too much what it looks like on some study, so why do it? I think our surveys, which were very accurate and in which we used the same script on everybody, were our best objective criteria of how they were swallowing. I think if we do a prospective multi-institutional study on the best way to handle the pylorus (ie, pyloromyotomy, nothing, or Botox), then we will have to build the cost of that in. Also, it will be harder to tell the patients that if they are doing well, they have to come back and have a swallow test at 3 or 6 months, but that might 
be the way to design it prospectively to really have data to answer the question. I am biased now and would favor the Botox group because I am convinced after doing all 3 procedures that it offers the best results.

Dr Bremner. Finally, you noted that the chemoradiation group had prolonged or delayed gastric emptying. Do you have a reason for this?

Dr Cerfolio. Well, I do not know the exact reason. I can guess. I am not sure, but I think it has to do with the fact that the conduit is now being radiated. It clearly is in the radiated field and then on top of a surgical manipulation, of grabbing it, stapling it, denervating it: all those things together add up.

Dr Bremner. I think that possibly a narrow conduit or Botox might be the answer, and I really look forward to participating in a prospective trial like you mentioned. Thank you very much, and thank you for the privilege of discussing the article.

Dr Cerfolio. Thank you.

Dr Richard Whyte (Stanford, Calif). Cerf, I enjoyed your article. It was really very good. I have a quick question, though. You had talked about using metoclopramide, erythromycin, and esomeprazol in these patients. Did you use that same combination throughout the years of the trial, or did that vary as well?

Dr Cerfolio. We were supposed to use it all the way through. If you looked at some of the first patients, they might not have gotten it every day postoperatively, but everyone was supposed to receive it. After that, though, our postoperative algorithms were well described with high compliance, and thus the vast majority of the patients have been receiving them all. We do not use the metoclopramide out for a month, but in the hospital we have been trying to do that. When I was at Mayo, I was lucky enough to spend time with Dr Keith Kelly, who is a general surgeon who spent a career working on gastric emptying, and I spent 3 months with him, so I always was very interested in gastric emptying, and we sort of stole some of his ideas for these patients. It is not really in the thoracic literature, but Dr Jessica Donnington has written a nice chapter on the use of this treatment in the thoracic surgical clinics.

Dr Donald Low (Seattle, Wash). First of all, as usual, this is a very innovative, very interesting, and appropriate idea that we should be looking at carefully regarding the management of these patients. I notice that, first of all, you use the shotgun approach. You start everything on everyone in every case before you do your assessment.

Dr Cerfolio. Yes, just like I coach my Little League teams: we come out running trying to steal bases early, and in basketball we start off with a full-court press right out of the shoot. We come out in the first inning and quarter and throw everything at them to win the ballgame. Absolutely.

Dr Low. That is great. Maybe as far as winning that is good, but maybe not for cost-effectiveness and assessing the results of overall outcomes. First of all, you do not do a kocherization?

Dr Cerfolio. No.

Dr Low. For those of us who do this regularly, we recognize sometimes the duodenum is very mobile. It is all ready. You can move it right up to the esophageal hiatus. In other situations it is very tacked down, and I think one of the issues regarding emptying is making sure your conduit is verticalized and straight and that the pylorus is sitting 2 to $3 \mathrm{~cm}$ below the hiatus in a straightforward way. Do you not think that should be a part of the assessment and the intraoperative aspects of what we are doing to ensure good emptying at the time of surgical intervention?

Dr Cerfolio. It is a great question. It is one of the flaws of the study course. One of the reasons I stopped doing a Kocher maneuver is that I am not convinced that it makes a difference. But I totally agree that the stomach should not be redundant or floppy because over time it always gets worse. If you see those patients back at 3 or 4 years and if they are alive and they have a big floppy conduit, they empty poorly. They look like they have long-standing achalasia with a sigmoid esophagus, and therefore I take out so much stomach when I am in the chest, not as much in the neck, that I asked myself why I was taking the time to do a Kocher maneuver when I am resecting so much stomach. The conduit was still straight and tall without the Kocher maneuver, it seemed. It took time: not much, but some. There is some risk, but not much, but everything is about efficiency and speed, and I think that the Kocher maneuver did not make a difference. Now it is funny how sometimes you do not do a Kocher maneuver and yet sometimes you still have a very nice straight column and sometimes you do not. If someone has had a previous operation and they are socked in there, I will take that down a little bit to try to ensure the conduit is vertical, but I know that patients do not need a formal Kocher maneuver to get a straight verticalized conduit.

Dr Low. One of the many things you are well known for is your clinical pathways and fast tracking. I assume that includes the reinitiation of dietary profiles after surgical intervention.

Dr Cerfolio. Right.

Dr Low. What we have found is that some of the aspects of aspiration, emptying, and so on have to do with what you are feeding the patient, and a lot of the feedback we get has to do with that barium swallow that you do at 4 days. Do you think that we are too far into clinical pathways and that we should be assessing these swallows ourselves to assess how we should be introducing erythromycin, metoclopramide, dietary profile, and Botox on an individual basis rather than for baseball teams and for surgical patients using ...

Dr Cerfolio. ... or basketball. That is another very good point. I think that the team is the critical thing, and it is really not the surgeon. You guys know I am not modest, but it is the team, especially with patients undergoing esophagectomy. I am, without a doubt, the most easily replaced part of the team. We now have several supernurses who just take care of the patients who have had esophagectomies. We have a team of swallowing specialist nurses, a speech and swallowing team that comes by and does these studies. We have radiologists who are very into doing this and making sure-because we have had a death in the radiology suite after a swallow-that it is being done correctly and safely. Therefore I think your point is right. There are some patients in whom probably you should not do a swallow test on the fourth or fifth day because it is just not safe. They are not ready. They do not pass their bedside swallow test, which we do on everyone first before we send them for a swallow test. If they have poor emptying and a column of barium in their conduit, then the radiologist places a soft small catheter through the anastomosis and sucks everything out to prevent aspiration, but I think your point is well taken.

Dr Jemi Olak (Bakersfield, Calif). How did you measure bile reflux in your patients in the postoperative period and then subsequently? 
Dr Cerfolio. We did not measure it scientifically, as you suggest, but we did measure it clinically. We have a survey that goes all the way from what they eat and how they eat to looking at their dumping symptoms. We ask things like whether they have any type of sensation of things coming up. A lot of these people had endoscopies afterward. Was there evidence of bile coming up? Pillow staining was a specific question they were all asked to assess for bile reflux as well. Therefore a very specific survey, I think, was the best way I could get a handle on it, but you are right, it is not scientific. It is not a radionucleotide tag particle that is bound to the bile molecule to see whether it is coming up, which would be nice but is really not practical or very cost-effective. Most importantly, if the patient is happy and asymptomatic, I am not sure what I would do with that information. 